\title{
Economic appraisal of deployment schedules for high-level radioactive waste repositories
}

\author{
Phuong Hoai Linh Doan ${ }^{a}{ }^{*}$, Thierry Duquesnoy, and Jean-Guy Devezeaux de Lavergne \\ French Atomic and Alternative Energy Commission, CEA/DAS, Paris Saclay University, 91191 Gif-sur-Yvette, \\ France
}

Received: 7 April 2016 / Received in final form: 30 June 2016 / Accepted: 16 March 2017

\begin{abstract}
The deep geological repository (DGR) is considered as the definitive management solution for highlevel waste (HLW). Countries defined different DGR implementation schedules, depending on their national context and political choices. We raise the question of the economic grounds of such political decisions by providing an economic analysis of different DGR schedules. We investigate the optimal timing for DGR commissioning based on available Nuclear Energy Agency (NEA) data (2013). Two scenarios are considered: (1) rescheduling the deployment of a DGR with the same initial operational period, and (2) rescheduling the deployment of a DGR with a shorter operational period, i.e. initial closure date. Given the long timescales of such projects, we also take into account the discounting effect. The first finding is that it appears more economically favorable to extend the interim storage than to dispose of the HLW immediately. Countries which chose "immediate" disposal are willing to accept higher costs to quickly solve the problem. Another interesting result is that there is an optimal solution with respect to the length of DGR operational period and the waste flow for disposal. Based on data provided by the Organisation for Economic Cooperation and Development (OECD)/Nuclear Energy Agency (NEA), we find an optimal operating period of about 15 years with a flow of $2000 \mathrm{tHM} /$ year.
\end{abstract}

\section{Introduction}

Radioactive waste is seen by many as an important issue for nuclear energy and finding suitable waste solutions remains a key obstacle for all stakeholders: the industry, regulatory authorities and the population. Most radioactive waste is generated by the nuclear industry, with the rest produced by hospitals for medical purposes, universities and defense-related activities. This waste is classified and managed according to its activity level and the half-life of its radionuclides. Nowadays, very-low-level waste (VLLW), short-lived low-level waste (SL-LLW) and short-lived intermediatelevel waste (SL-ILW), which represent most of the waste produced in volume (more than 90\%) is being disposed of safely in near-surface repositories in many countries. The remaining - including long-lived intermediate-level waste (LL-ILW) and high-level waste

\footnotetext{
$\overline{\mathrm{a}} \mathrm{PhD}$ student in long-term economics of radioactive waste management

* e-mail: phuong-hoai-linh.doan@cea.fr
}

$\left(H L W^{1}\right)$ - is currently stored in spent fuel ponds and interim storage facilities pending a definitive disposal option. HLW accounts for over $95 \%$ of the total radioactivity and remains hazardous for up to 100,000 years so it cannot be managed permanently on the surface or subsurface. The deep geological repository (DGR) is now considered by most countries (USA [1], France [2], Sweden [3], etc.) as the reference solution for the definitive management of high-level radioactive waste. However, discussions are still ongoing about when to switch from surface storage to deep geological disposal. The timing of DGR implementation is conditioned by three types of constraints:

- technical constraints mainly due to the decay of radionuclides and waste heat transfers;

- waste flow management constraints;

- political and institutional preferences.

Given the importance of the HLW management issue for every nuclear country, the DGR implementation schedule is defined by political choices. In France, for example, it is fixed by the '2006 Act on nuclear waste

\footnotetext{
${ }^{1}$ HLW is available in 2 forms: spent nuclear fuel (SNF) and waste material that remains after SNF reprocessing.
} 
management'. However, the economic grounds of such political decisions should be addressed; an economic analysis for assessing different DGR implementation schedules may help clarify these choices. The issue of HLW management has been recognized in many NEA technical publications over the years, e.g. NEA (2010) [4] and NEA (2014) [5]. There is, however, little information available in the economic literature: Gollier and Lavergne [6] and Loubergé et al. [7] are two specific examples. It could even be affirmed today that there is still insufficient academic work focusing on the analysis of DGR economics.

The main purpose of this article is to evaluate the optimal timing for spent nuclear fuel/high level waste (SNF/HLW) disposal on purely economic grounds. Without focusing on a particular country, we are proposing a generic model for the inventory of 30,000 metric tons of heavy materials (tHM) in the form of SNF. Our numerical illustrations are mainly based on the NEA cost estimation (2013) [8] of the nuclear fuel cycle, with certain additional assumptions based on expertise provided by the French Atomic and Alternative Energy Commission (CEA). Firstly, we provide an overview of the waste disposal schedules in various different countries. Secondly, we examine the constraints that influence the DGR implementation schedule. Thirdly, we analyze any variations in the HLW management costs (including storage and disposal costs) as function of the DGR start-up date, and identify conditions for choosing this date from an economic perspective. Finally, we evaluate the waste flow issues. It seems that some DGR schedule decision-makers implicitly assume that the waste flow for disposal should correspond to the HLW production flow. This assumption is challenged in this paper.

\section{International overview on HLW/SNF management: a trans-historical problem}

Most countries now consider deep geological disposal as the standard solution for the final management of long-lived radioactive waste, with each country having reached a different level in the implementation of their DGR program. Some notable advances have been observed in Finland, Sweden and France where disposal operations are planned to begin around 2020. For each of those two Scandinavian countries, a spent fuel repository design has been developed, a site has been selected and the construction license application has been submitted to the authorities. In Finland, numerous studies have been underway in five potential areas to select an appropriate disposal site since 1987. In early 2015, the Finnish authority for radiation protection and nuclear safety (STUK) gave the greenlight to build the DGR for spent fuel after having examined the construction license application filed in 2012. This repository is expected to start operating in 2020 [9]. In Sweden, Söderviken was announced as the site chosen for their DGR of SNF in 2009, with the corresponding construction license application submitted to the Swedish Nuclear Safety Authority (SSM) in March 2011. According to the Swedish nuclear fuel and waste management company (SKB), the DGR will be commissioned in 2030 [10] if all goes as planned. In France, the commissioning date for the DGR is set for 2029 [11]. The French have designed a single repository composed of different disposal areas to accommodate each waste category (LL-ILW and HLW). According to the implementation schedule drawn up by French national radioactive waste management agency (ANDRA), during the early years of disposal operation, the top priority during the first few years of operation is to deliver LL-ILW to the DGR until a peak is reached. Thereafter, slightly exothermic HLW packages will be placed in the repository. After 70 years of commissioning, the delivery of LL-ILW packages should drop to zero, while the disposal of highly exothermic HLW packages should continue until 2144.

On the other end of the scale, some national programs, including those of Germany and the United States, have suffered from public and political opposition. As a result, they have come up against considerable delay and difficulties. In Germany, a final repository site for spent fuel and HLW still remains to be chosen even though the nuclear phase-out has already been implemented. Underground exploration work was carried out to qualify the Gorleben salt dome. However, this disposal project was halted due to strong opposition from the German Green party in July 2013 and is now pending a new site selection procedure. In the US, although a deep geological waste repository is already operating in New Mexico for defenserelated waste ${ }^{2}$ (Waste Isolation Pilot Plant), Nevada is showing classic Nimby ${ }^{3}$ resistance to the proposed Yucca Mountain repository for utility HLW. For the time being, this project has been suspended. The future remains unclear, but it is probable that long-lived radioactive waste and spent fuel will be transferred to a DGR for disposal.

\section{Constraints on the implementation schedule of DGR projects}

As mentioned in the introduction, the implementation schedule of any DGR depends on three types of constraints: HLW heat transfers, waste flow management and political decisions.

\subsection{HLW heat transfers}

Waste package heat transfers in a DGR are a key parameter in the repository design and safety analysis. HLW packages need to be 'cooled' and shielded for several decades before they can be placed in a repository safely. During this cooling period, the heat production drops considerably due to the decay of short-lived nuclides. HLW can then be placed in the DGR, making sure there is sufficient space between each package to comply with the geological thermal constraints (e.g. $90^{\circ} \mathrm{C}$ limit in a clay formation in France). The longer the cooling period, the less the decay heat; this makes it possible to design a more

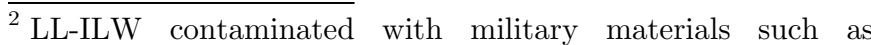
plutonium.

3 "Not in my back yard" opposition by residents to a proposal for a new development close to where they live.
} 


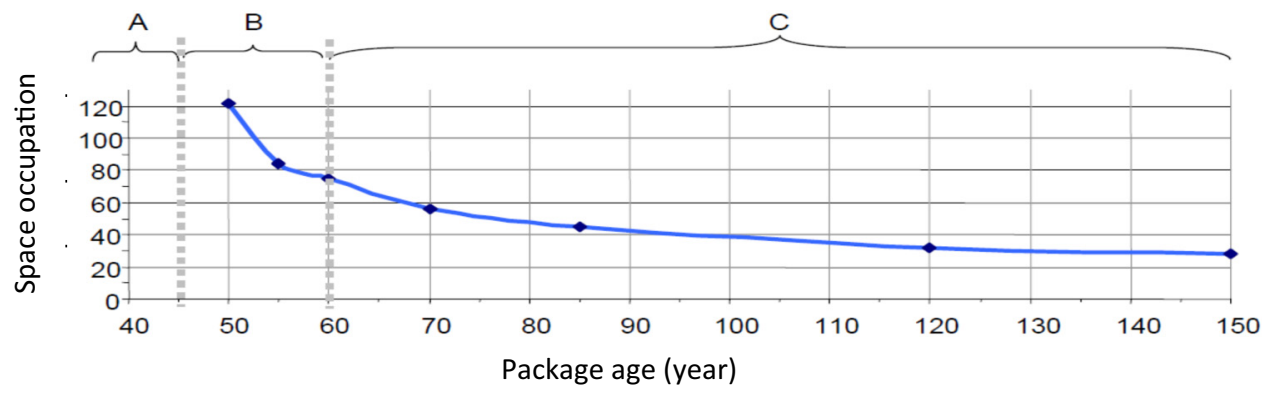

A: Technically impossible ( $<45$ years); B: Excellent package age sensitivity ( $45-60$ years); C: Lower sensitivity ( $>60$ years)

Fig. 1. Impact of the cooling period on the space required for waste package disposal (French clay concept) [12].

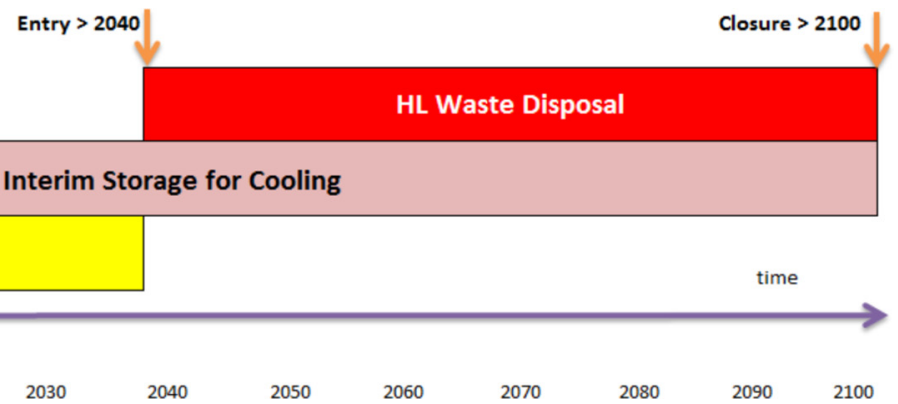

Fig. 2. Example of waste disposal schedule (stylized case study).

compact - hence cheaper - repository. In the case of the French disposal site (in clay), the disposal space could be reduced by roughly $35 \%$ if the interim storage period of the waste was prolonged for another 20 years (see Fig. 1 [12]). Therefore, the Department of Energy (DOE) in the US has decided to separate defense and commercial nuclear waste disposal facilities [13]. The idea is to open a first repository for the disposal of defense-related radioactive waste whose amount is essentially stable and known. A large fraction of this waste is older and 'cooler' than utility spent fuel. For this reason, a military waste repository may be faced with fewer constraints but it could provide valuable operating experience when designing the repository for utility spent fuel. Pending the construction of a repository, such spent fuels will benefit from heat decay in interim storage. Beyond a certain period ( 80 years), however, the annual heat decay becomes insignificant. As a result, future decisions related to high-level radioactive waste management will necessary involve a trade-off between a suitable cooling period in interim storage facilities and the entry date of waste into the DGR.

\subsection{Waste package flow management}

After reactor irradiation, HLW/SNF needs to be shielded and cooled in spent fuel ponds for a few years prior to being transported to a waste reprocessing site (for a closed fuel cycle) or to an interim storage facility (for an open fuel cycle) where the waste continues to cool down for at least 5-10 decades so it does not damage the repository due to the release of decay heat. In this paper, we have simplified our analysis by supposing an open fuel cycle in a generic model; however, further research shows that the results are very similar for a closed cycle. Assuming a fleet of nuclear power plants operating between 1980 and $2040^{4}$ and an SNF cooling period of 60 years, the DGR could not open until 2040 and the waste disposal operations would not end before 2100 (Fig. 2).

\subsection{Political and social aspects}

Each country has its own legislation on nuclear waste management which governs the disposal facility's safety standards, funding, implementation schedule, and stakeholder commitment. ${ }^{5}$ Such a policy is influenced by many specific factors such as the national energy strategy (e.g. nuclear phase-out in Germany), regional and international guidelines, financial resources, the radioactive waste characteristics, and the national fuel back-end strategy (open or closed fuel cycle). There is also the way in which public confidence and acceptance is forged and maintained, particularly with respect to people living in the siting area. Good examples are those of Finland and Sweden where local communities have a rather high level of trust in their regulator and in those designing and building the repositories. However, the opposite can exist in other countries where pro-nuclear and anti-nuclear parties have

4 This assumption on the operating period of the current nuclear fleet will not affect our results. It simply influences the waste flow management of the DRG.

${ }^{5}$ For example: in France, we have the Planning Act concerning the management of radioactive materials and waste (2006), Decree 15/01/2016, The Law $(15 / 07 / 2016)$ specifiying the modalities for a reversible deep geological repository, etc. In Sweden, The Nuclear Activities Acts (1984), etc. 
reached a deadlock, resulting in a very complex political and energy context. The key issue is achieving consensus so all the stakeholders can make a decision. Such situations generate delays in the possible implementation of deep geological repositories.

\section{Relevance of an economic appraisal for managing DGR schedules}

\subsection{Methodology}

The DGR schedule must comply with many requirements, including technical efficiency, environmental protection, safety, social feasibility, etc., while reaching a consensus among stakeholders (state, industrial, public, etc.). Considering the scarcity of budgetary resources, it is essential to integrate the economic aspect into the multicriteria analysis of all expenditures, including the longlived waste management cost. The economic analysis helps clarify certain questions of the public and policy makers: What will we gain or lose by making this investment, and what will we gain or lose by postponing such a decision?

At first sight, the method appears simple by seeking to support projects whose cost exceeds its benefits. However, the evaluation is much more complex when we integrate the time value into the decision-making process. Knowledge of public investment, particularly in the future, can only be imperfect. In the presence of unmeasurable uncertainties, several decision-making criteria can be proposed: the Maximax criterion for optimistic decisionmakers seeking the maximum possible result, the Maximin criterion for pessimistic decision-makers seeking the minimum possible payback, or the "MiniMax Regret" criterion wherein the decision implying the lowest level of regret is chosen. The main difficulty lies in choosing which criteria should be used when faced with uncertainty. However, in reality, it is rare that we have absolutely no information on the probability of future events. We tend to operate in a world of "risk" (known probabilities) rather than 'uncertainty' (unknown probabilities). Thus, how should we make the DGR decision in such risky conditions, particularly when it has consequences far into the future? For this reason, the discounting method was applied in this economic appraisal $[14,15]$.

Time has its own value, and an identical cash flow is more valuable today than in the future. The discounting method helps us to deduce the current value of a future expense and to calculate the net present value of a longterm project. It defines the effort limit that the current generation is prepared to grant for the future and determines the investment effectiveness for the DGR project. There are other methods that can be used for comparing different timeline values, such as the internal return rate or saving return rate. In this paper, however, the cash flow discount method was chosen. This article does not set out to justify this choice or to highlight the limits of using this very "classical" method, but rather to evaluate its influence in the specific context of high-level radioactive waste management.

\subsection{Specificities associated with the long-term economic assessment of deep geological waste disposal}

There are two types of discount rates: private rate and government rate[16]. The private rate used by companies to calculate their net present values is higher than the government rate due to their stronger sensitivity to the market variations. The long-term economic assessment of radioactive waste disposal may vary depending on the different visions: an assessment carried out by a public authority could differ greatly from an assessment done by a nuclear operator. For the long-lived waste disposal, the choice of these rates is governed by various points below:

- The operating period of any waste disposal project ranges from 50 to 150 years. Over such a long period, the relative prices of many goods and services will evolve with respect to the economy changes. Particularly, the costs of health and environment will also increase at least at the economy growth rate. Therefore, in the absence of a detailed economic analysis, lowering the discount rate is one way to take into account potential impacts on ecosystem and public health of a project (e.g. the DGR).

- Uncertainties and risks on the estimated cash flow must be integrated into the analysis due to the length of the study period. Quantifying these risks is also a difficult task. We need to reduce the discount rate to take into account these "risks on risks" [17].

- Cash flows are always negative in the case of a radioactive waste disposal project. The expenses are covered by a fund set up by the companies that generate the waste (as in France) or by the state in the form of an output tax (as in the US). The fact that the cash flows are negative must push to lower the discount rate in a precautionary approach.

- Waste disposal projects are governed by laws. However, the only microeconomic assessment with the usual rates would not confirm the decision to dispose of radioactive waste compared with the interim storage solution. Thus, the intention to deploy a solution that has no burden on future generations means choosing a very low or zero rate in the disposal program in order to obtain a schedule that is coherent with the law.

All these points justify a relatively low discount rate for the long timescales associated with any DGR project. Instead of defining a specific discount rate in this paper, however, the calculations were performed using a range of discount values from $0 \%$ to $5 \%$ (updated to 2016) to emphasize the impact of this key economic parameter on $\mathrm{SNF} / \mathrm{HLW}$ management costs.

\section{Application}

\subsection{Estimating waste disposal costs}

There are differences in the SNF management costs between countries depending on their back-end strategy (direct disposal, partial recycling or multiple plutonium recycling), the waste volumes for disposal, safety principles, geological conditions, local costs (e.g. labor costs), 


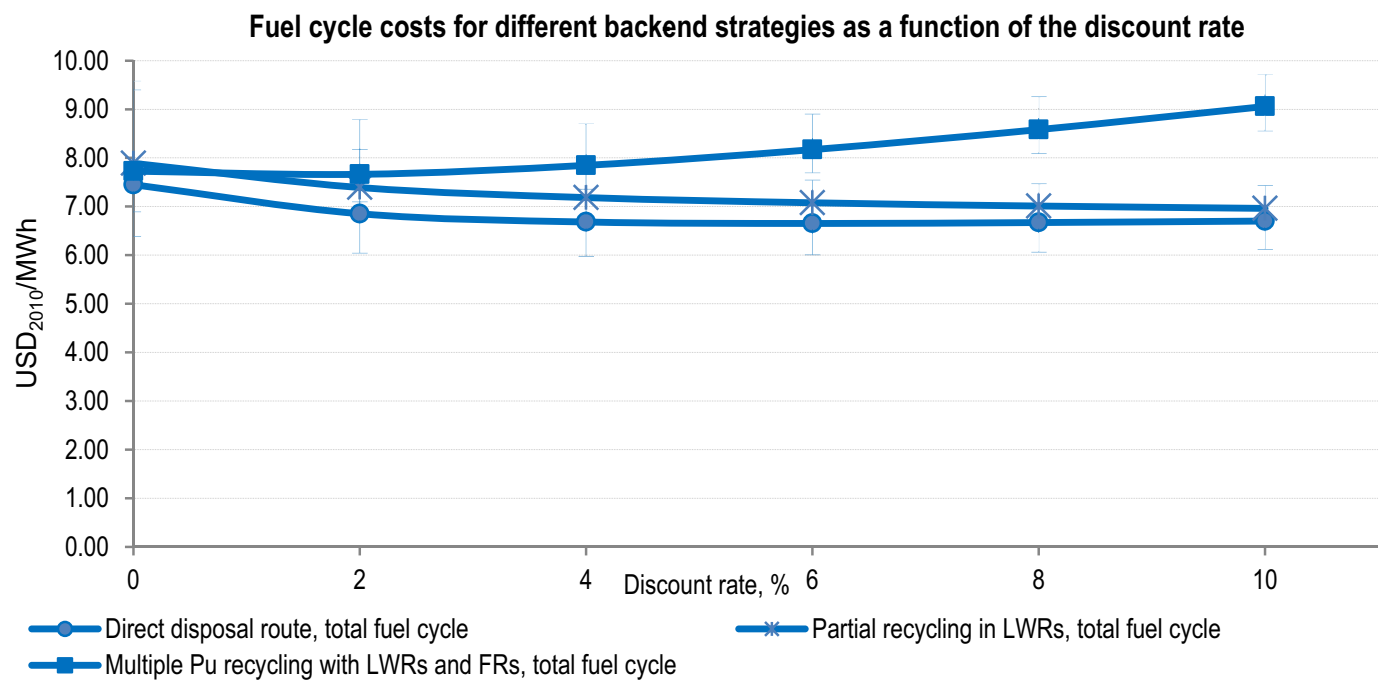

Fig. 3. Fuel cycle costs for different back-end strategies as a function of the discount rate for a fleet generating $400 \mathrm{TWh} / \mathrm{year}[8]$.

national policies, and technologies, etc. The total waste management cost involves many parameters, notably studies, construction (civil works, equipment, etc.), operation (personnel, maintenance, electricity), and closing phase.

Three main options are currently being considered for the long-term management of SNF: direct disposal (SNF is used once and is then considered as HLW ready for disposal), partial recycling option (SNF is reprocessed to recycle unused uranium and plutonium in light water reactors (LWR) and multiple plutonium recycling (single MOX and REPUOX recycling in LWR and multiple plutonium recycling in fast reactors). The cost of each SNF management strategy depends on the subsequent stages and facilities required for its implementation. For direct disposal, the overall cost or the cost set includes the interim storage cost, waste encapsulation cost (packaging and preparing SNF for disposal) and the disposal cost. The reprocessing and recycling strategies require more facilities, so their cost sets are broader, consisting of interim storage costs, reprocessing costs and encapsulation costs, along with final disposal costs. However, the NEA study (2013) on back-end cycle economics showed that the fuel cycle cost differences between the three back-end strategies is relatively small whatever the discount rate (see Fig. 3). More specifically, the fuel cycle costs for the two most frequently used options in the world (direct disposal and partial recycling) are very similar. The investments in facilities for SNF reprocessing, such as reprocessing plants, MOX fuel fabrication plants and vitrification plants which are required for the recycling strategy, increase its back-end costs as compared with the direct disposal option. Yet, these additional costs are offset by the benefits of purchasing fresh fuel. Thus, the difference in fuel cycle costs between these two different back-end strategies is negligible. In other words, it seems feasible choose one reference option (the direct disposal strategy in our case) as the basis for the fuel cycle cost calculation discussed below. The results are not very sensitive to the backend option.
Moreover, in this study, instead of focusing on a particular country, we are proposing a generic model with some additional theoretical assumptions:

- The SNF is stored for at least 60 years before being encapsulated and placed in the DGR (direct disposal).

- The quantity of waste for disposal is 30,000 tHM produced by a fleet of LWRs operating between 1980 and 2040 .

- All storage cells required for HLW shielding and cooling are progressively built over 60 years from the start of interim storage needs (1985).

- The encapsulation facility and the DGR are deployed at the same time. They are planned to start in 2040 and to close in 2100 .

- Closure costs of the encapsulation facility and interim storage are negligible compared with the cost of DGR closure.

- All costs are expressed in $\mathrm{M}_{2010}$ and are levelized to 2016.

- Waste flows are given in tHM/year.

Simple calculations based on the average aggregated worldwide data [8] resulted in the following the back-end costs for the reference scenario.

\subsubsection{Interim storage costs}

As mentioned above, interim storage is required for spent fuel cooling before disposal. The storage cost covers the investment cost and the operation and maintenance (O\&M) costs of storage facilities (wet or dry storage) (Fig. 4):

- There are two types of investment: (1) overnight initial investment (yellow) needed to build the basic facilities which are independent of the storage capacity

\footnotetext{
${ }^{6}$ Wet storage: ponds in which spent fuel is stored under water after unloading from the reactor. Dry storage: dry cask storage allows spent fuel that has already been cooled in spent fuel ponds for several years to be surrounded by inert gas inside a container called a cask [18].
} 


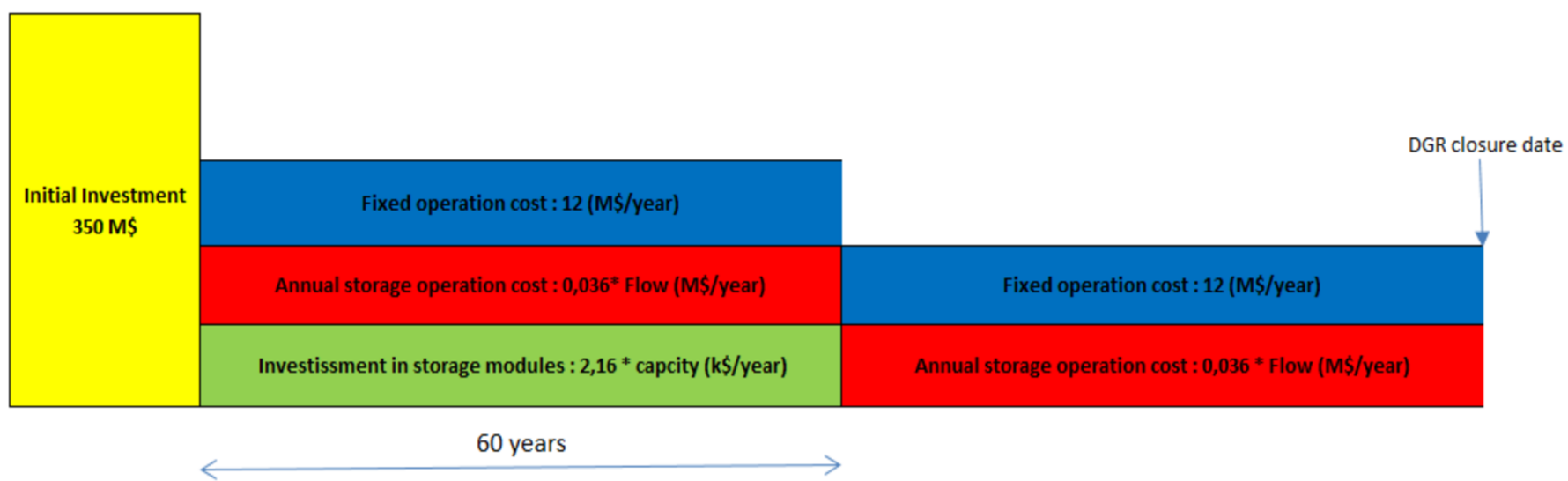

Fig. 4. Breakdown of interim storage costs.

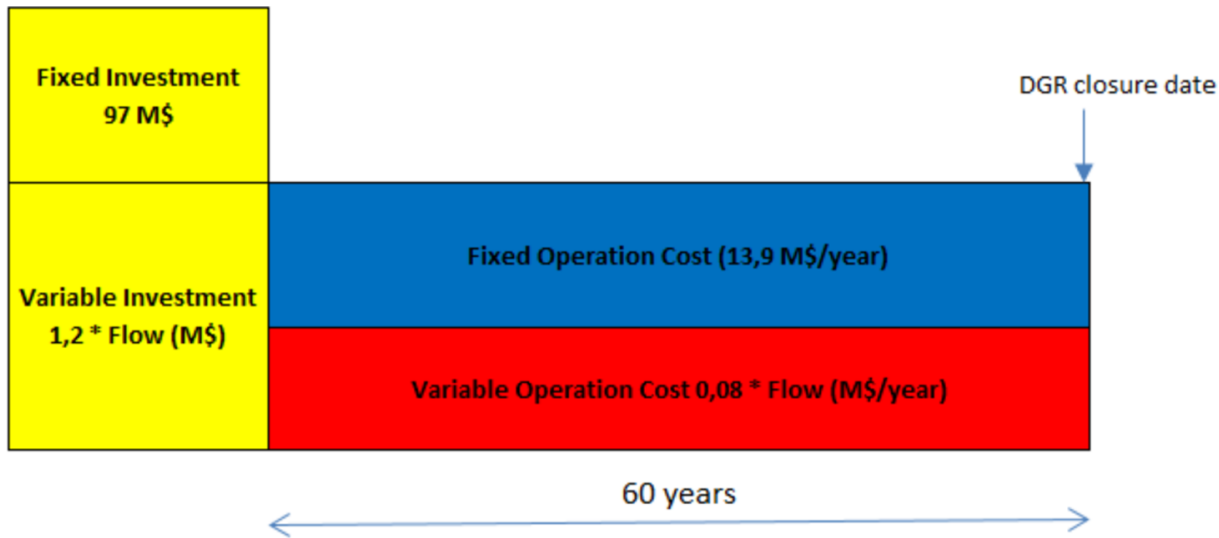

Fig. 5. Breakdown of encapsulation costs.

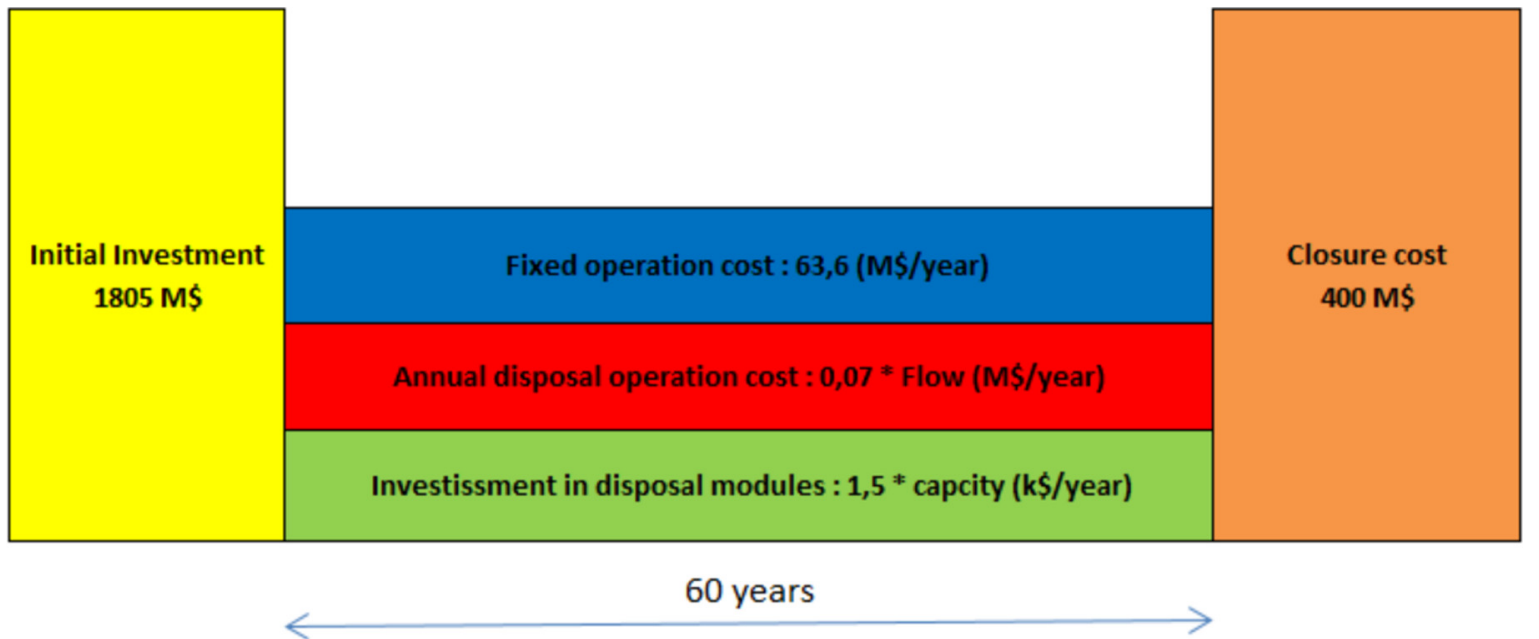

Fig. 6. Breakdown of disposal costs.

(e.g. technical facilities). For reasons of simplicity, we have supposed that the initial constructions could be completed overnight; (2) incremental investment (green) for the gradual construction of storage cells during operation.
- After 60 years, as assumed above, all the modules reserved for the total waste quantity are operational. As a result, we no longer need to invest in the construction of storage modules' construction anymore. Annual expenditures are then spent on maintaining the storage facility 
operation, consisting of fixed costs (water, electricity, personnel) (blue) and a variable cost component parametrized as a function of the HLW flow (red).

\subsubsection{SNF encapsulation costs}

Similarly, this involves overnight investment (yellow), including a fixed part and a variable part that is proportional to the annual HLW quantity to be managed, and the O\&M costs which are also composed of fixed (blue) and variable portions (red) (Fig. 5).

\subsubsection{Disposal costs}

These costs include three components (Fig. 6):

- Investment costs, which include fixed and variable parts: its fixed component (yellow) corresponds to the overnight initial investment in surface facilities and shaft construction which are independent of the repository capacity, for example access ramps, wells, technical installations, etc. Its variable component (green) is roughly proportional to the volume of material excavated underground, explicitly the HLW waste volume, e.g. due to the drilling and construction of disposal galleries and cells.

- The operational cost has fixed (blue) and variable portions (red) which are roughly proportional to the HLW flow for disposal.

- The overnight closure cost (orange) which is roughly independent of the quantity of waste for disposal.

The economic assessment mentioned in the following is based on these costs and assumptions.

\subsection{Numerical results}

This section details the impact of rescheduling the deployment of a DGR on the total cost of the project based on the back-end cycle cost data and assumptions provided in Section 5.1. It also determines if it is economically favorable to rapidly dispose of HLW. DGR implementation decisions are obviously conditioned by political choices. Yet, the question of whether the economic appraisal is consistent with legislative and regulatory texts is worth being considered. The effect of rescheduling DGR deployment on back-end costs is analyzed separately in two different scenarios: (1) rescheduling the deployment of a DGR with the same initial operational period, i.e. closure date is pushed back, and (2) rescheduling the deployment of a DGR with a shorter operational period, i.e. initial closure date, to avoid burdening future generations of HLW/SNF management.

\subsubsection{Effect of rescheduling DGR deployment with the same operational period}

This section discusses the simplest case of DGR schedule management where all the timescales are simply pushed back in time, while retaining the same cost structure and operating arrangements (see Fig. 7).

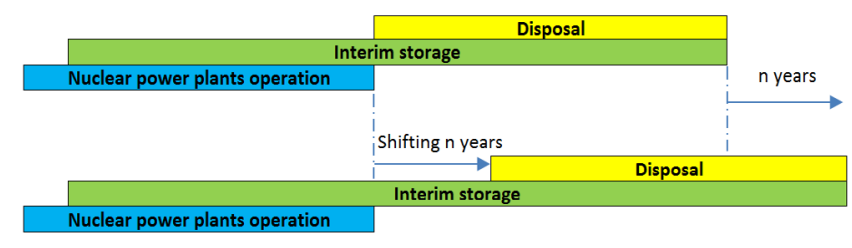

19801990200020102020203020402050206020702080209021002110

Fig. 7. $n$-year sliding of the DGR schedule.

By postponing the implementation schedule for the SNF encapsulation facility and the DGR, the waste cooling period is extended, resulting in increased storage costs (in red in Fig. 8). In case of $n$-year delay, we have:

$$
S(n)=S(0)+A \sum_{i=1}^{n} \frac{1}{(1+r)^{t_{\text {end }}+i-t_{0}}},
$$

with $S(n)$ : the storage cost if disposal opening is delayed for $n$ years, $S(0)$ : the storage cost until the planned closure date of the DGR $\left(t_{\text {end }}\right), t_{0}$ discounting year (2016), $r$ discount rate, $A$ annual storage cost (detailed above).

However, the raw disposal and encapsulation costs (non-discounted) remain constant due to the unchanged timescales (in blue in Fig. 8), assuming there is no technical progress or project cost slippage. The impact of the increased storage costs thus leads to a rise in the total project cost. In the case of a very small discount rate, the result remains the same as shown in the first graph of Figure 8 with a discount rate of $0 \%$.

Nevertheless, as soon as higher discount rates are taken into account (greater economic value of the time) (see Sect. 4), the effect of DGR rescheduling is to delay the high expenditures of the project. The net present value of disposal therefore decreases quickly with the project rescheduling.

$$
\operatorname{DGR}(n)=\frac{\operatorname{DGR}(0)}{(1+r)^{\left(t_{p}+n-t_{0}\right)}},
$$

where $\operatorname{DGR}(n)$ - the levelized disposal cost if the DGR opening is delayed for $n$ years and $\operatorname{DGR}(0)$ - the levelized disposal cost if all goes as planned.

For discount rates higher than $1 \%$, the reduction in disposal costs largely compensates for the storage costs. Therefore, on the basis of an economic approach focusing on expenditure management with the "usual" discount rates, it is not economically relevant to quickly dispose of $\mathrm{SNF} / \mathrm{HLW}$ compared with the storage strategy. When the discount rate is high, it is more economically favorable to deploy DGR at a later date rather than immediately.

However, long-term storage has never been considered as a definitive solution for SNF/HLW management because of its permanent monitoring requirements. In Finland, Sweden and France where significant progress has been made in their disposal programs, neither the nuclear operators nor the governments have in mind to delay the implementation of their DGR. Any delay in these countries will be mainly due to technical problems, 

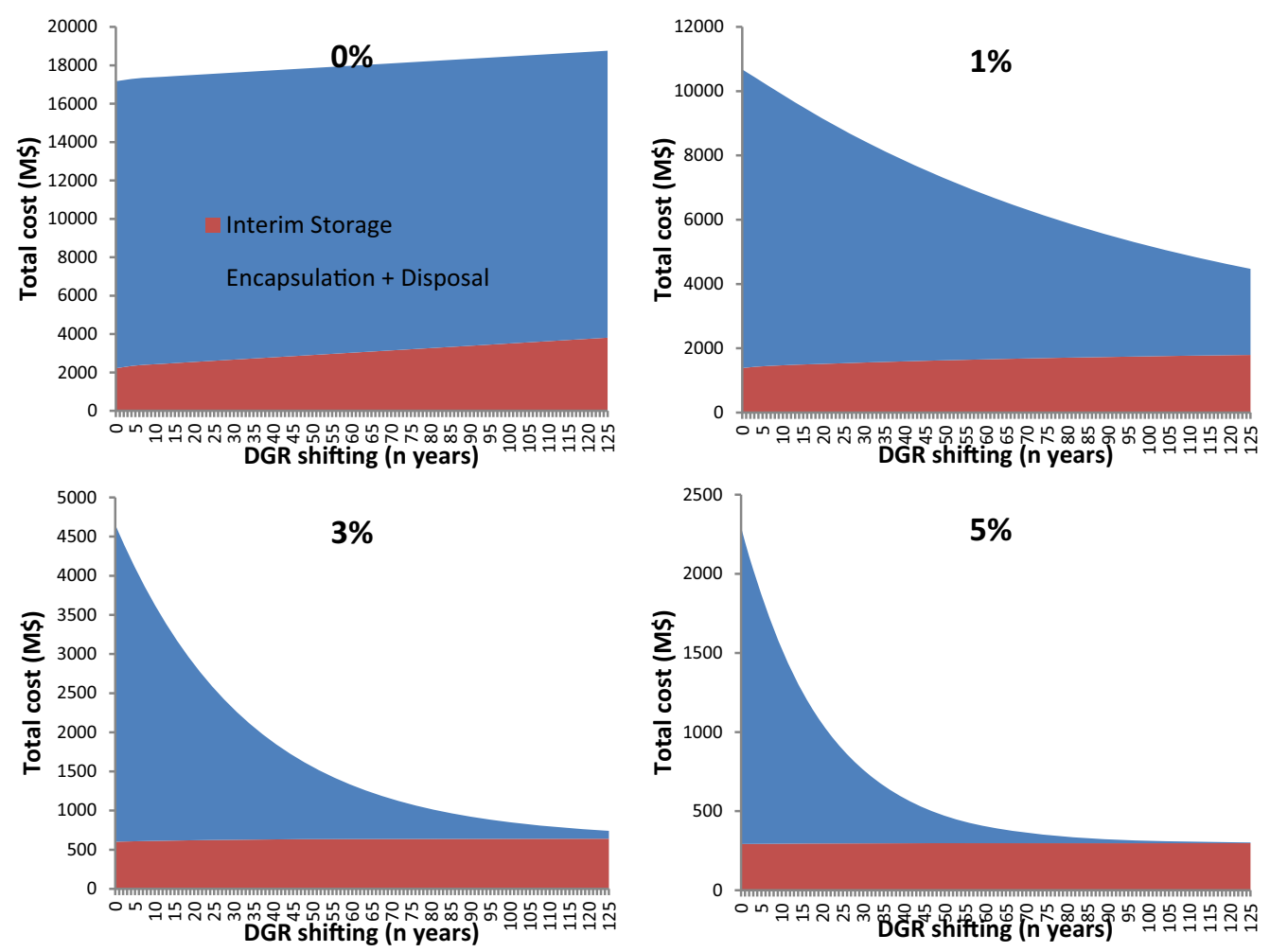

Fig. 8. Effect of rescheduling DGR deployment for $n$ years with different discount rates.

safety requirements or social opposition. Therefore, apart from the above cost factors, we may integrate another annual expense into our model: $R \& D$ costs. If the delay in DGR deployment is due to progressive reprogramming steps, the R\&D activities in underground laboratories (e.g. Onkalo, Aspö and Bure respectively for the abovementioned countries) and the local integration programs (e.g. regional economic development support) are going to continue, at least until DGR implementation. On the contrary, if it is decided to significantly delay the implementation of the DGR project in a single step, $R \& D$ expenditures may be adapted: they will decrease but continue for a longer period. In this paper, we have only taken into account the first situation: stable and continued R\&D expenditures assumed to cost roughly $\$ 65 \mathrm{M} /$ year $^{7}$ (in green in Fig. 9).

$$
R(n)=R(0)+A^{\prime} \sum_{i=0}^{n-1} \frac{1}{(1+r)^{t_{p}+i-t_{0}}},
$$

where $R(n)$ - the expenditure on $\mathrm{R} \& \mathrm{D}$ if the DGR implementation is postponed for $n$ years, $R(0)$ - the amount spent until the planned DGR opening $\left(t_{p}\right)$ and $A^{\prime}$ yearly $R \& D$ expense.

Because R\&D spending represents a relatively small fraction of the total levelized cost of HLW/SNF management, the findings above remain valid (Fig. 9). It is

\footnotetext{
$\overline{7}$ CEA estimation of the annual expenses for maintaining the research laboratory activities, French Atomic and Alternative Energy Commission.
}

still economically relevant to delay DGR deployment, but with a smaller gain. In addition, beyond a certain period (80 years), the back-end costs decrease very slow; as a result, the delayed DGR entry date no longer offers any significant gain.

In conclusion, when the "usual" discount rate $(\geq 1 \%)$ is applied, long-term storage is the cheapest HLW/SNF management solution. Some countries have adopted this "wait and see" strategy, for example in Netherlands where the parliament has chosen long-interim storage (at least 100 years) as their current SNF management strategy. This decision is principally due to the fact that there is only a small quantity of long-lived waste quantity to be managed, which poorly supports DGR implementation for this country alone because the economies of scale are very important for this type of facility. In general, economic reasons have never taken precedence over the fact that DGR deployment removes the burden on future generations. Our results should thus be interpreted by the fact that countries chosen the "immediate" disposal solution are willing to accept the higher costs in order to quickly resolve the problem of long-lived radioactive waste and to relieve future generations of such a burden. These overcosts are non-negligible; they can reach a factor of 3 with the discount rate of $5 \%$ (Fig. 9) or even 8 if the national policy has decided to not carry out any $R \& D$ or local support programs (Fig. 8).

The first analysis focuses on the choice of the DGR opening date. However, it is also possible to take into account the date when the whole waste inventory has been placed in the repository (DGR closure date). It is no longer a question of quickly demonstrating the existence of the 

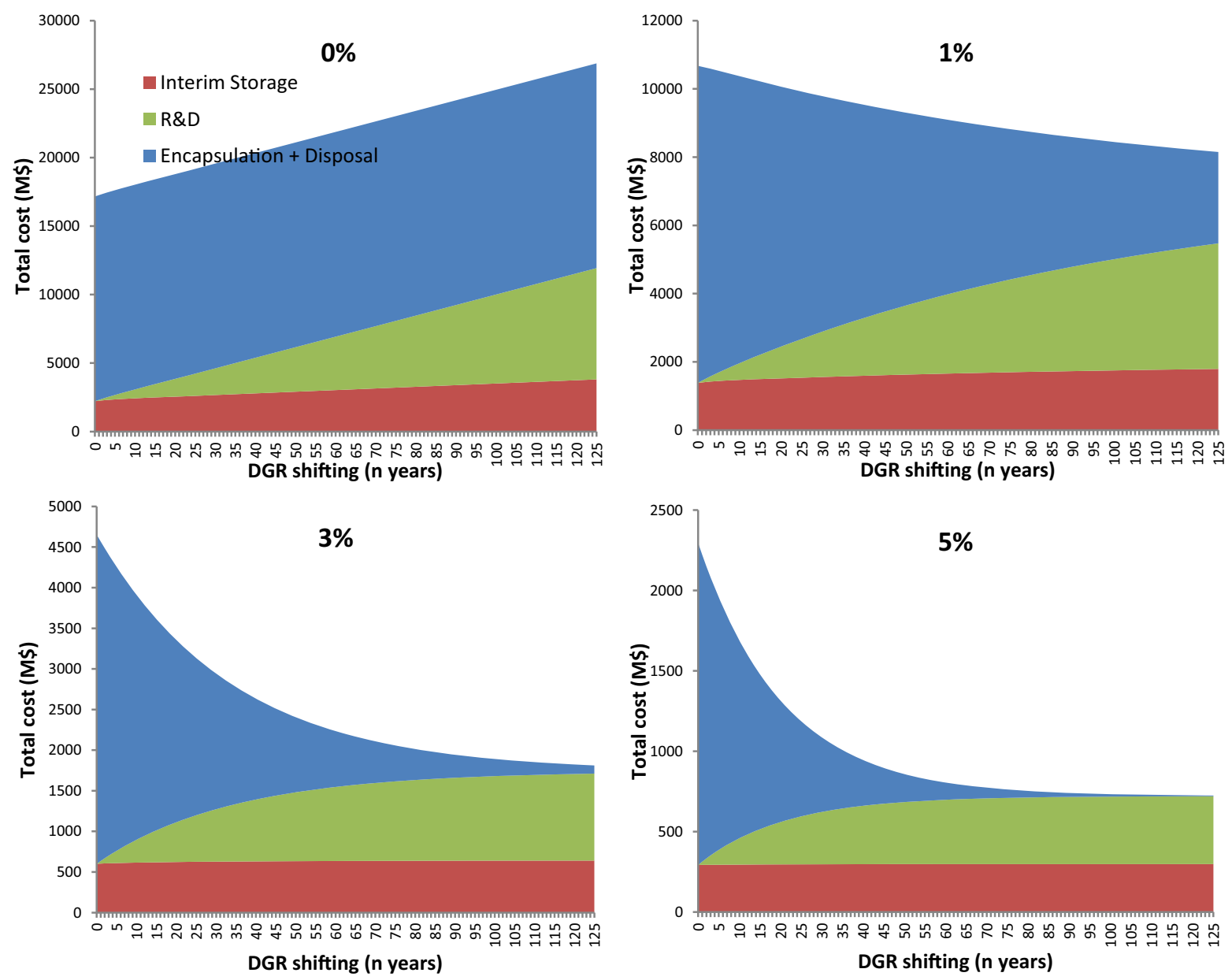

Fig. 9. Effect of rescheduling DGR deployment with the same initial operating period for $n$ years with different discount rates (for countries with research laboratories).

long-lived waste solution and its implementation, but rather to focus on the date when future generations will be completely free of the waste management burden. This raises another question: is there an optimal solution that maintains the same DGR closure date (to avoid transferring the burden to "our grandchildren") but with a later implementation date. This solution may reach the minimum project cost (in terms of the levelized value).

\subsubsection{Effect of rescheduling DGR deployment} with maintaining the initial closure date

Another strategy analyzed in this section involves rescheduling the DGR startup while leaving its closure date unchanged. The generation benefitting from the electricity produced remains responsible for defining and implementing a safe radioactive waste management solution.

As shown in Figure 10, the duration of waste package delivery period is shortened when the DGR startup date is pushed back but the initial closure date is maintained. This therefore increases the annual waste flow into the DGR. In order to effectively manage such a "high flow" rate, it would be necessary to increase the initial investments (e.g. building extra access galleries), with

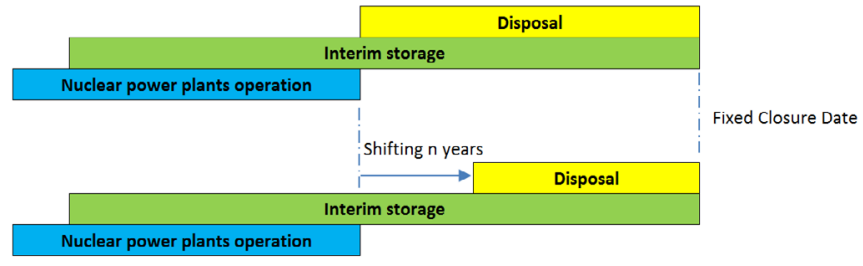

19801990200020102020203020402050206020702080209021002110

Fig. 10. $n$-Year delay of DGR deployment with an unchanged closure date.

the yearly operational costs of the encapsulation plant and the DGR also increasing. However, the fact that the duration of the waste disposal operations is shorter may reduce the total cost of the project (see Fig. 11). Moreover, the longer the DGR implementation schedule is delayed, the 'cooler' the first waste packages will be when they are transferred to the DGR. Therefore, waste management would be cheaper because the waste density per $\mathrm{km}^{2}$ in the DGR will be higher (more compact repository design). The interim storage costs would remain more or less constant due to the unchanged closure date, which is not represented in Figure 11. 

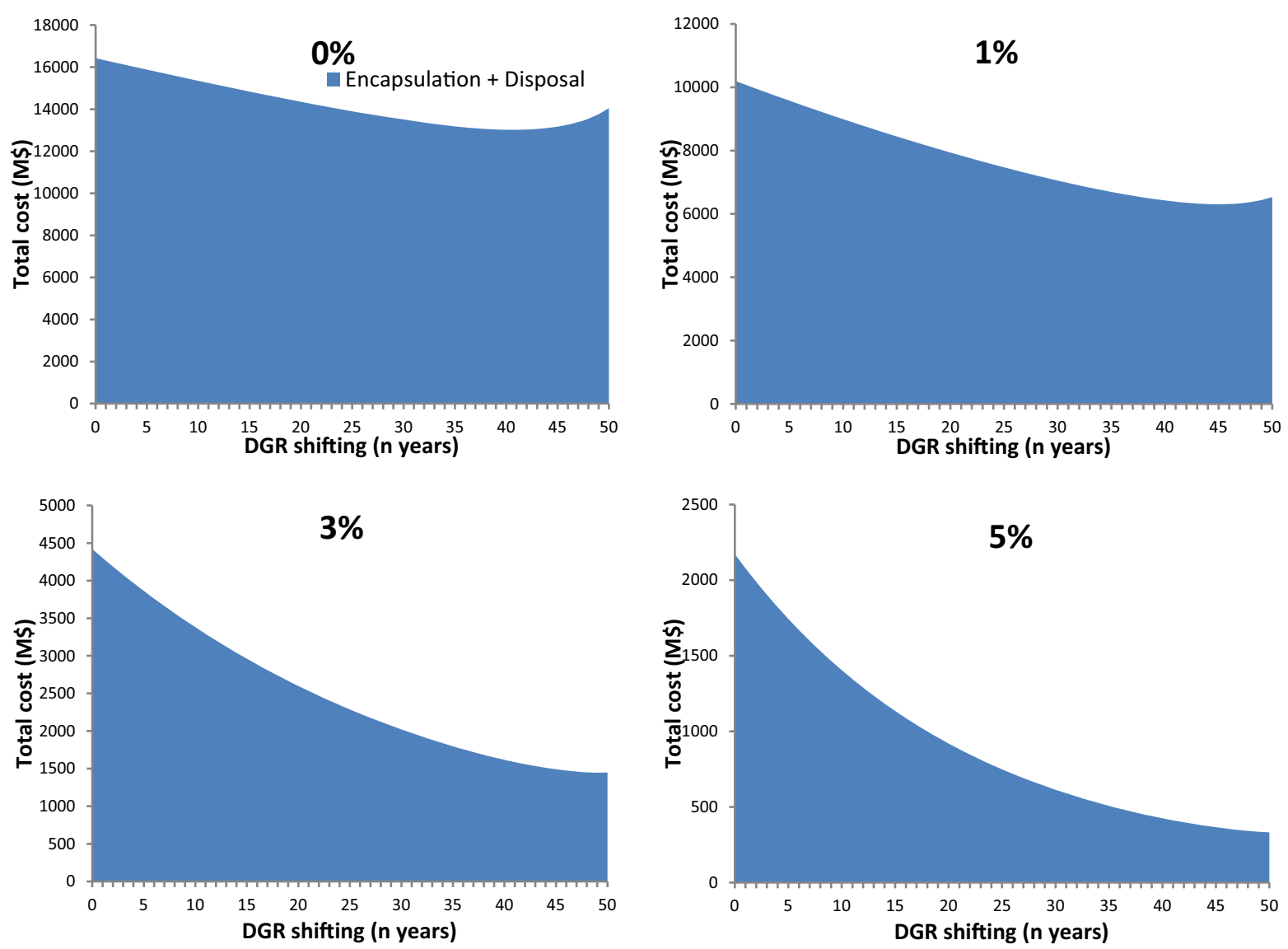

Fig. 11. Effect of reprogramming DGR deployment for $n$ years while maintaining the initial closure date.

Based on our assumption on the increased investment and annual operation costs as a function of the waste flow for disposal (see Sect. 5.1), we noticed that a DGR with a high HLW flow preferable, even with a discount rate below 1\% (Fig. 11). With an unchanged DGR closure date, the longer DGR deployment is delayed, the lower the total management costs of HLW/SNF. The shorter operational period largely offsets the initial investment increase and that of the annual operation costs. Beyond a certain point (shifting DGR for over 45 years), however, the cost reduction becomes insignificant due to the excessively high flow to be managed. Delaying the project may no longer be profitable or even unfavorable with low discount rates $(\leq 1 \%)$. High waste flows into the DGR would greatly increase the investment and annual operation costs for which the gains due to the shorter operational period could no longer compensate. For countries where there has been marked progress in the project preparation (whether in terms of R\&D or local economic development), vast sums of money continue to be spent every year to maintain research in underground laboratories and to support local activities. Inversely, a very long postponement of DGR deployment may increase the total HLW/SNF management costs (Fig. 12). There is therefore an optimal solution with respect to the duration of the disposal operations and the annual waste flow for disposal. Based on the NEA data and our theoretical assumption (detailed in Sect. 5.1), the "optimal" solution would be to dispose of 30,000 tHM (the total waste inventory for a generic case) over approximately 15 years with a waste flow of $2000 \mathrm{tHM} /$ year. Any longer delay would be disadvantageous. These results must, however, be confirmed by further studies with a more accurate estimate of the investment increase as a function of the waste flow.

\subsection{Extensions}

Thus far and based on the "usual" positive discount rates, the current economic appraisal has shown that DGR deployment delays lead to lower back-end costs. However, the economics is only one of many factors influencing decisions with respect to SNF/HLW management. Many other qualitative aspects need to be considered during the decision-making process. Some of them relate to national policies (regulatory aspects, energy transition strategy, etc.), some concern social issues (public acceptance, environment effects, etc.), while others have a more technical slant (nuclear power renewal, fast reactor development strategy, dynamics of technical progress, safety, etc.). Different factors may outweigh others according to specific national contexts and different temporal contexts.

- For countries that rely heavily on nuclear power such as France and the US, their initial choices are the same: "immediate" deployment with the dual objective of acting now without passing on the burden to future generations 

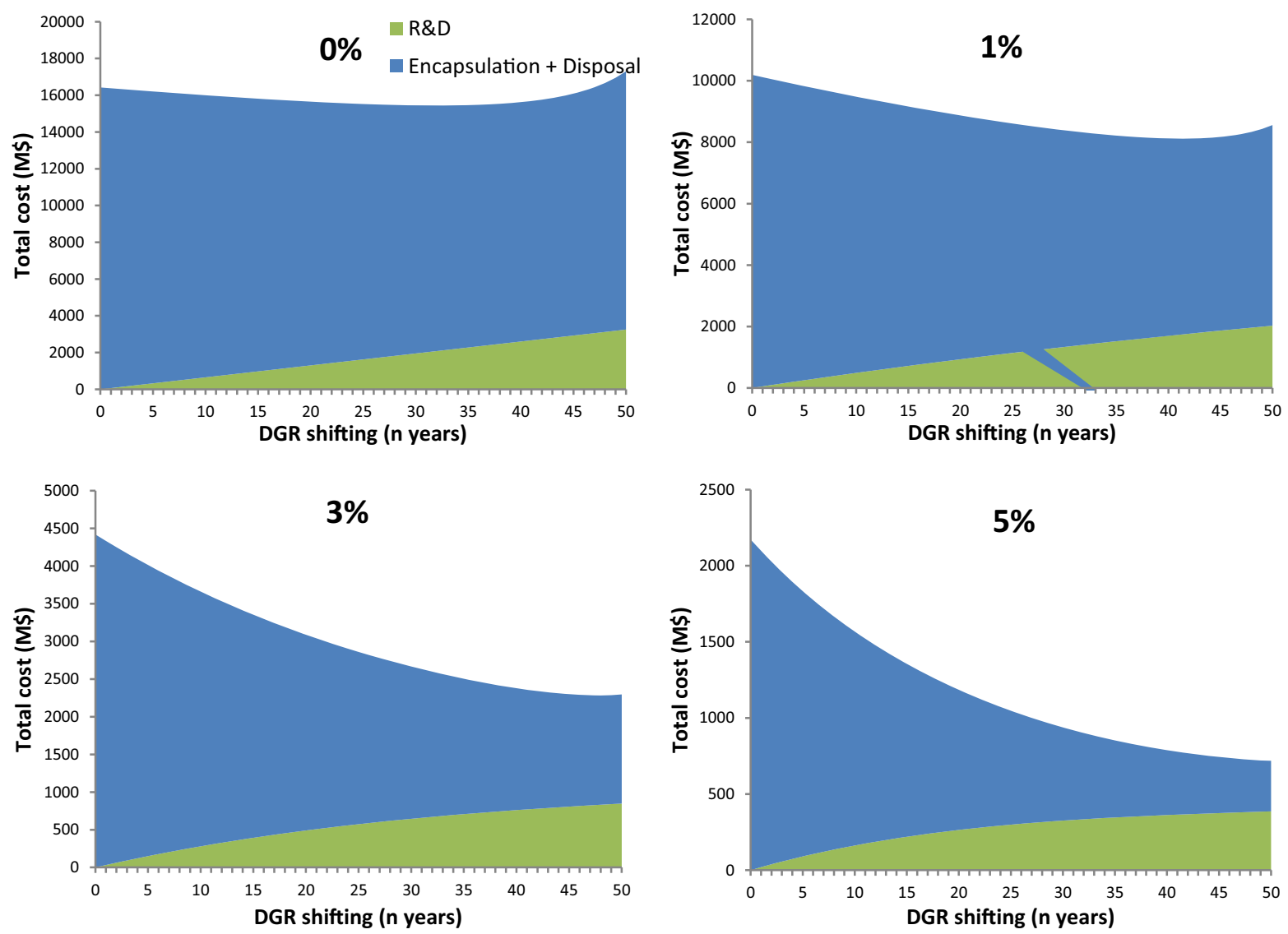

Fig. 12. Effect of reprogramming DGR deployment for $n$ years while maintaining the initial closure date (with R\&D).

and of continuing to develop nuclear energy. France is still pursuing this strategy, even though the total project costs exceed 20 billion euros [19]. Demonstration of DGR feasibility and an appropriate legislative schedule are now necessary in order to achieve tangible progress. Finland and Sweden are in comparable situations [20,21]. In US, social and technical feasibility difficulties associated with the Yucca Mountain project add undoubtedly further delay to the opening of the DGR.

- For countries with small nuclear programs and hence a smaller waste volume for disposal, whether in nuclear phase-out (Italy) or nuclear development (Netherlands), HLW/SNF should be stored in interim storage facilities rather than choosing immediate disposal in a DGR, in the hope of finding a common definitive solution for many small nuclear industries. This solution would be much more economical due to the important economies of scale. According to NEA data (2013), the construction of 10 identical deep repositories with a capacity of $3000 \mathrm{tHM}$ is a far more expensive solution than building a single DGR with a capacity of 30,000 tHM $(10 * 6.3 \mathrm{~b} \$ \gg 9 \mathrm{~b} \$)$. This notion may benefit countries that are faced with economic or expertise constraints when it comes to building their own infrastructure. Yet, the likely opposition of the public to accept radioactive waste from a foreign country makes this solution improbable in the near future.

- For countries that depended on nuclear power but are currently following a phase-out strategy (e.g. Germany), all existing nuclear, including interim storage facilities, have or will be completely decommissioned. In this case, the DGR is considered as the end point of the decommissioning.

\section{Conclusion}

For all countries involved in nuclear activities, whether for electricity production, medical purposes, research \& development, or other military and industrial purposes, they are all faced the same question: what should be done with radioactive waste? Most of this waste (including short-lived low- and intermediate-level waste) generally benefits from a well-developed treatment process. The remaining waste ( $\mathrm{SNF} / \mathrm{HLW}$ ) accounts for a very small proportion of the total radioactive waste volume $(\leq 10 \%)$, though it represents almost all the radioactivity. This waste is still pending for a definitive solution. Some countries are more advanced than others, but almost all converge on the same solution: deep geological disposal. Given the long timescales involved, the timing with respect to deciding to deploy a DGR is one of the key nuclear issues and remains the main public concern in many countries. This paper addresses this issue by analyzing the different DGR deployment schedules from an economic perspective, which should help guide decision-makers when it comes to managing timescales.

We have compared the back-end costs of different deployment schedule strategies for managing SNF and HLW. We have always included a discount rate and 
substantiated the use of levelized costs, but we systematically examined a broad set of discounting levels. The principle is simple: we computed the total discounted costs based on the assumption of different startup dates. In addition, we either kept or changed the initial closure date (i.e. length of disposal operations) in order to minimize the HLW/SNF management costs. The objective in the case of keeping the initial closure date is to highlight the fact that some national programs are built on the implicit assumption that the waste flows going into the repository must be equivalent to the waste flows coming out of the reactors and this assumption needs to be challenged.

Our numerical illustrations are based mainly on a data set provided by the NEA [8], with certain additional assumptions based on expertise from the CEA.

Our first main finding is that it always appears more economically favorable to extend the interim storage of $\mathrm{SNF} / \mathrm{HLW}$ than to dispose of the waste immediately, when taking into account the usual discount rates $(\geq 1 \%)$ and assuming that such a scenario is technically and politically feasible. The more we delay DGR deployment, the more we save in terms of the total HLW management costs. Firstly, this is due to the fact that high project expenditures will be delayed in time. Secondly, this is due to the prolonged waste cooling period, which decreases the overall cost of waste disposal because cooler waste packages allow for a more compact repository design. Examples can be found in the US, Netherlands and Canada, where national strategies appear to follow the economically optimal choice: long-term storage for SNF/ HLW. In addition, long-term storage is much more preferable for countries with a small volume of radioactive waste for disposal (like Netherlands), with the hope of finding a common disposal building for many small nuclear industries. This solution would be significantly cheaper due to the economies of scale. However, not every country makes the same decision (long-term storage). Other countries, such as Finland, Sweden and France have decided to deploy DGR projects, with an opening date that is mainly conditioned by technical and social development steps. The principle is to act as soon as possible. This strategy is based more on political than economic criteria. This solution is certainly a more expensive choice, but may appear more ethical when considering the future generations. In such a strategy, present generations bear all the responsibility of their own radioactive waste and do not impose any undue burdens on future generations (as long as the relevant safety requirements are applied). In addition, this immediate disposal option increases the public's acceptance of nuclear power, which is an indispensable criterion for developing the nuclear energy.

Our analysis also highlights the fact that there exists an optimal solution with respect to the duration of the waste disposal operations; a shorter operational period appears to be more favorable. We fixed the disposal closure date and evaluated the trade-off between the waste cooling period and the duration of the disposal operations. Based on NEA data, our results show that the economically optimal duration is around 15 years (with a flow of $2000 \mathrm{tHM} /$ year). This means that the waste flows going into the repository can differ from the flows coming out of the reactors (the operational period being shorter than reactor operation). However, shorter periods that lead to excessively high waste flows will strongly increase the initial investment (e.g. building extra access galleries) and hence the total management costs.

It is of course evident that an economic assessment is insufficient when it comes to choosing the deployment timescales for this definitive SNF/HLW solution. A multicriteria approach should be adopted by taking into account all factors, qualitative or quantitative. Some effects go against a "simple" economic vision, and any delay in the DGR deployment schedule could result in a number of inconveniences that are not reported here. For this reason, additional cost factors should be integrated into our model, such as the social value of "immediate" disposal, accidental risks due to extended interim storage periods and risks during disposal operations, etc. The model would also require with more realistic parameter values that accurately reflect the pace of technological progress, the energy context, economic growth, changes in social acceptance, etc. Moreover, like other sociopolitical issues, the process of SNF/HLW management depends strongly on national contexts. In addition to this general economic assessment, it is worth carrying out a specific analysis of each country's decision-making process that taking into accounts its own national priorities and public attitudes. Our future papers will try to respond to these issues.

\section{References}

1. The Nuclear Waste Policy Act (United States of America, 1982)

2. The Planning Act concerning the management of radioactive materials and waste (France, 2006)

3. The Nuclear Activities Acts (Sweden, 1984)

4. NEA, Optimization of geological disposal of radioactive waste, national and international guidance and questions for further discussion (OECD, Paris, France, 2010)

5. NEA, Preservation of records, knowledge and memory across generation, monitoring of geological disposal facilites Technical and societal aspects (OECD, Paris, France, 2014)

6. C. Gollier, J.-G.D. Lavergne, Analyse quantitative de la réversibilité du stockage des déchets nucléaires, Economic et Prévision, Options Réelles 1-13 (2001)

7. H. Loubergé, S. Villeneuve, M. Chesney, Long term risk management of nuclear waste: a real options approach, J. Econ. Dyn. Control 27, 157 (2002)

8. NEA, The economics of the back end of the nuclear fuel cycle (OECD, Paris, France, 2013)

9. Source from POSIVA - Finnish expert organization responsible for the final disposal of spent nuclear, http://www. posiva.fi/

10. Source from SKB - Swedish nuclear fuel and waste management company, http://www.skb.com/

11. Source from ANDRA - French national radioactive waste management agency, http://www.andra.fr/ and http:// www.cigéo.com/ 
12. Audition of CNE-National committee of evaluation (France, 2005)

13. Platts, Nucleonics Week, Volume 56, Number 13, (March 26, 2015), available on the site www.platts.com

14. C. Gollier, Quel taux d'actualisation pour quel avenir? Revue d'économie financière 66, 253 (2002)

15. S. Bayer, Generation adjusted discounting in long-term decision-making, in Paper presented on the International workshop "Reflections on Discounting: Ethical and Economical approaches", Island of Vilm (1999)

16. S. Dautremont, J.G. Lavergne, Optimisation des choix d'investissements énergétiques et prix du temps: quel taux d'actualisation choisir? Revue de l'Energie 604 (2011)
17. Centre d'analyse stratégique, Le calcul du risqué dans les investissements publics, La documentation française, Rapports \& Documents 36

18. International Atomic Energy Agency (IAEA), Survey of wet and dry spent fuel storage (IAEA, Vienna, Austria, 1999)

19. Decree related to the cost of the long-term management of intermediate level long lived waste and high level waste (France, 2016)

20. Posiva, Cost estimate of Olkiluoto Disposal Facility for Spent Nuclear Fuel, Working Report (2005)

21. SKB, Costs from and including 2015 for the radioactive residual products from nuclear power, Technical Report TR-14-16 (2014)

Cite this article as: Phuong Hoai Linh Doan, Thierry Duquesnoy, Jean-Guy Devezeaux de Lavergne, Economic appraisal of deployment schedules for high-level radioactive waste repositories, EPJ Nuclear Sci. Technol. 3, 12 (2017) 